\title{
Staple and Wooden Diet: Foreign Bodies in a Traumatised Tooth with Periapical Pathology
}

\author{
Prabhakar AR, Saraswathi VN and Manjunath \\ TG* \\ Department of Pedodontics and Preventive Dentistry, \\ Bapuji Dental College and Hospital, India \\ *Correspondling author: Manjunath TG, Department \\ of Pedodontics and Preventive Dentistry, Bapuji Dental \\ College and Hospital, Davangere, Karnataka-577004, \\ India
}

Received: January 28, 2017; Accepted: March 03, 2017; Published: March 20, 2017

\begin{abstract}
Self-introduced foreign object by children into the root canal of carious or traumatically injured tooth is often reported in the literature. It is more common to find this situation in children as it is a well-known fact that children often tend to have the habit of placing foreign objects in the mouth. Sometimes the foreignobjects get stuck in the root canals of the teeth, which the children do not reveal to their parents due to fear. These foreign objects may act as a potential source of infection and may later lead to further complications. This case report describes self-introduced unusual foreign bodies and their successful retrieval from root canal of maxillary right central incisor.
\end{abstract}

Keywords: Foreign bodies; H-file; Non-surgical technique; Traumatized tooth

\section{Introduction}

Numerous cases have been reported in literature till date depicting the presence of unusual foreign bodies such as metal screws [1], darning needles [2], staple pins [3], beads [4], penciland leads [5], nails [6] plastic chopsticks [7], incense sticks [8] lodged in the pulp chambers or root canal of a cariously involved or traumatically injured deciduous and permanent teeth. Most of these cases are diagnosed by chance on routine radiographic examination of the tooth associated either with infection, pain, swelling or recurrent abscesses as a sequelae to the pulpal exposure and lodgement of the foreign body and usually parents are unaware because either the children are themselves unaware of these entrapments or they are scared to inform their parents.

Consequence of child's habit of placing foreign objects into the mouth may cause injury to both the hard and soft tissues, and also the extrusion of foreign body into periapical area increases when the involved tooth has an open apex which requires highly skilled pediatric dentist as well as complicated techniques along with lot of patience for the retrieval of such foreign objects especially in children, which is quite challenging. As the removal of foreign object from the root canal is a complicated procedure, which is managed either by removal from the root canal without changing the canal morphology of the root canal or it must be bypassed [9]. It also requires careful instrumentation, irrigation and floatation to remove the obstruction from the canal [10].

The present case report describes a pediatric patient with selfintroduced unusual foreign bodies in the root canal of maxillary right central incisor and its successful conservative management.

\section{Case Presentation}

A fourteen year healthy male patient reported with his father to the Department of Pedodontics and Preventive Dentistry, Bapuji Dental College \& Hospital, Davangere with a chief complaint of pain and pus discharge from upper front tooth region from past 15 days.
The patient gave history of trauma 16 months back \& gave no history of undergoing any treatment for the same. On taking further history the patient revealed the habit of using wooden sticks and metallic objects to remove the accumulated food from within pulp chamber of the fracture tooth in order to relieve discomfort.

Intra oral examination of the patient revealed

(a) An oblique fracture of middle third of the crown i,e Ellis class III fracture and discoloration was seen w.r.t right maxillary central incisor (Figure 1).

(b) Presence of draining sinus on the gingiva near the apex of right maxillary central incisor.

(c) Right maxillary central incisor was tender on percussion.

The tooth in subject showed no response to either thermal or electric pulp test (EPT) whereas all other maxillary anterior teeth were normal in all regards. Intra oral periapical radiograph revealed the presence of radiopaque linear foreign object in the apical one third of the root canal of maxillary right central incisor and also large periapical radiolucency with a well-defined border was seen in relation to the same tooth (Figure 2). A provisional diagnosis of nonvital maxillary right central incisor with associated periapical cyst and foreign body lodgement was made.

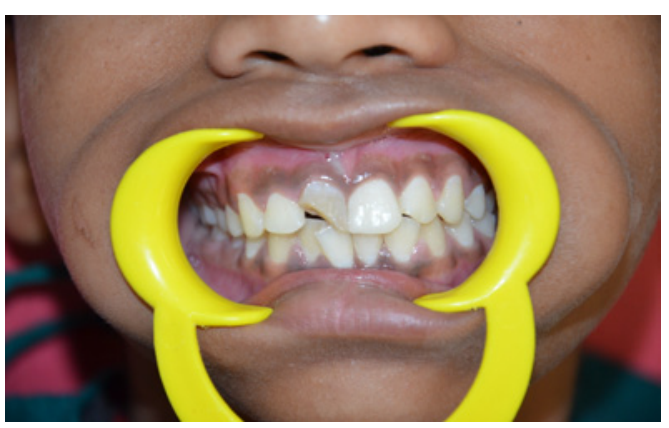

Figure 1:
Citation: Prabhakar AR, Saraswathi VN and Manjunath TG. Staple and Wooden Diet: Foreign Bodies in a Traumatised Tooth with Periapical Pathology. Austin J Dent. 2017; 4(2): 1070. 

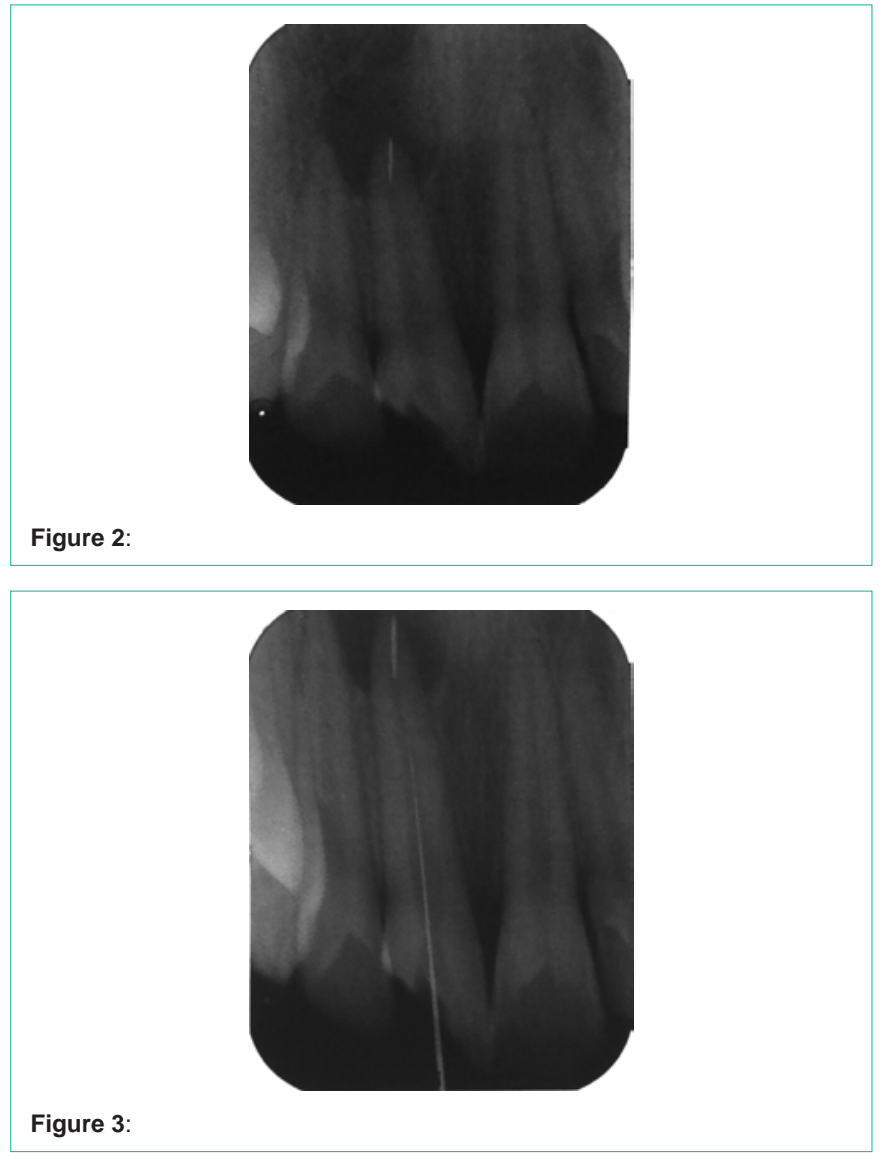

After evaluating the clinical and radiographic evidences patient's parent was then explained about the retrieval of the foreign object followed by endodontic therapy and aesthetic restoration and informed consent of patient's parent was obtained before starting the treatment.

\section{Treatment}

Retrieval of foreign object: The tooth in subject was isolated under rubber dam and access cavity was prepared. The debris from pulp chamber was cleaned by copious irrigation with $5.2 \%$ sodium hypochlorite and physiologic saline. After the removal of food debris and necrotic contents from the pulp chamber. An ISO no. $15 \mathrm{H}$-file (DENTSPLY Maillefer, Ballaigues, Switzerland) was used to bypass the foreign object (Figure 3). The foreign object was not visible from access cavity clinically as it was snugly stuck into the apical one third of right maxillary central incisor. Retrieval of foreign object was attempted using a non-surgical technique i.e. by bypassing the no. $15 \mathrm{H}$-file (DENTSPLY Maillefer, Ballaigues, Switzerland) and by attempting to engage the object between ISO no. $15 \mathrm{H}$-file (DENTSPLY Maillefer, Ballaigues, Switzerland) and canal wall then pulling it out coronally followed by copious irrigation with normal saline and 5.2\% sodium hypochlorite. But during retrieval several grass sticks were retrieved among which the largest was measuring about $1.2 \mathrm{~cm}$ and then two of were about $5 \mathrm{~mm}$ in length. Once all the grass sticks were retrieved a metallic foreign object measuring $5 \mathrm{~mm}$ was retrieved by using similar method and a radiograph was taken to confirm the sucessive retrieval of the metallic foreign body (Figure 4A and B). Finally working length was determined (Figure
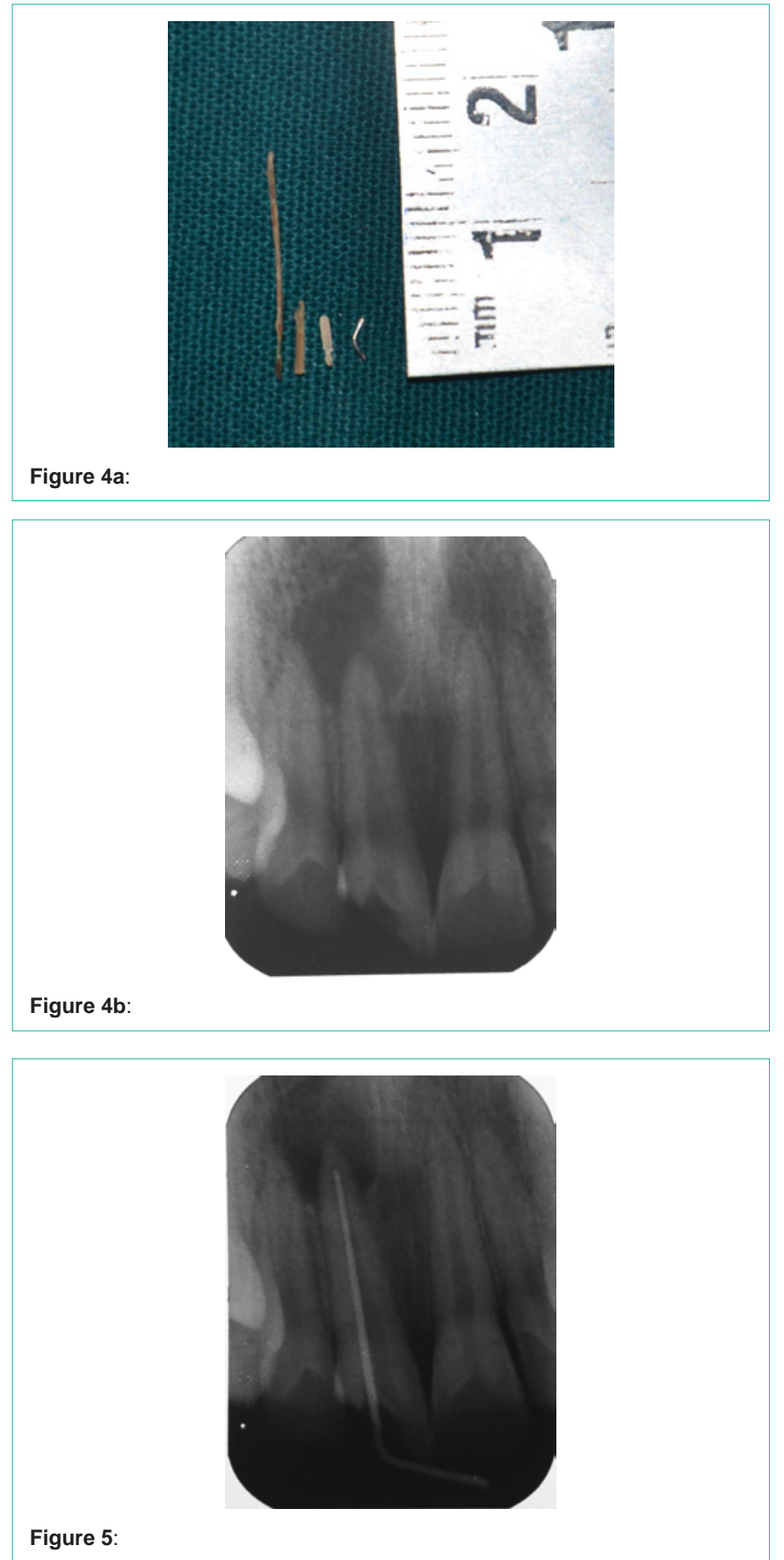

5) and a calcium hydroxide dressing was given for a period of one week followed by triple antibiotic paste dressing (Figure 6). The intra canal cleaning and shaping was done using step back procedure and using $5.2 \%$ sodium hypochloride and saline as irrigants. In the next visit obturation (Figure 7) was done and restored with Glass ionomer cement (GC Fuji II).

\section{Discussion}

Children are notorious and they often try to explore things around them which sometimes lead to traumatic outcomes. Different types of foreign objects like metal screws [1], darning needles [2], staple pins [3], beads [4], penciland leads [5], nails [6], plastic chopsticks [7], 


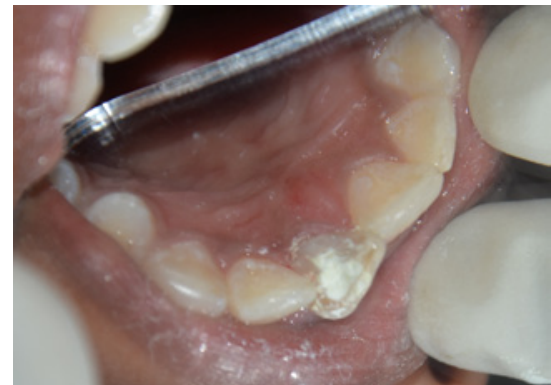

Figure 6:

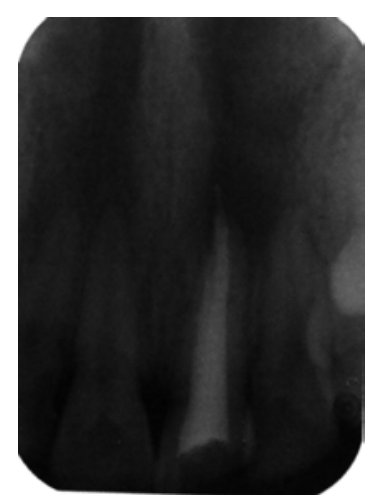

Figure 7:

incense sticks [8], are seen to be most commonly lodged in the pulp chambers or root canal of a cariously involved or traumatically injured deciduous and permanent root canals, which have been reported in the literature. In the present case, the patient reported with the chief complaint of pain and pus discharge from the upper front tooth since 1month. Patient gave history of trauma to the maxillary right central incisor due to fall from bicycle 1 year back. The clinical examination revealed Ellis class III fracture of the right maxillary central incisor with open access to the pulp chamber and sinus opening was present with respect to same tooth. On radiographic examination a radiopaque object was seen at the apical one third of the root canal. On taking further history patient revealed that he used wooden sticks and stapler pins to remove the food entrapped within the tooth to relieve the discomfort caused by the food entrapment.

Literature suggests various methods for the retrieval of foreign objects from the root canal, like use of ultrasonic instruments [11], the Masserann kit [12], modified Castroveijo needle holders [13], and also Ethylene diamine tetra acetic acid has been suggested as a useful aid in lubricating the canal when attempting to remove the foreign object. The Steiglitz forceps have also been described for use of removal of silver points from the root canal. There is a description of an assembly of a disposable injection needle and thin steel wire loop formed by passing the wire through the needle being used. This assembly was used along with a mosquito hemostat to tighten the loop around the object [14] Nehme [15] had recommended the use of operating microscope along with ultrasonic filing to eliminate intracanal metallic obstructions.

Srivastava and Vineeta [16] have suggested periapical surgery or intentional reimplantation to remove such objects. McCullock [17] suggested that access to the foreign object is improved by removal of small amount of tooth structure. According to Walvekar, et al. [18], if the foreign object is snugly bound in the canal, the object may have to be loosened first; it should then be removed with minimal damage to internal tooth structure to prevent perforation of the root.

Complications can follow if these impacted foci of infection are not eliminated at the right time. Actinomycosis following placement of piece of jewellery chain into a maxillary central incisor has been reported by Goldstein [19], Chronic maxillary sinusitis of dental origin developed due to pushing of foreign bodies into maxillary sinus through the root canals was reported by Costa [20].

\section{Summarry}

The present case report discusses the management of tooth with impacted foreign objects in the apical one third of maxillary right central incisor, where in successful retrieval of piece of stapler pin was accomplished with a simple conservative technique. i.e., by engaging the object between ISO no. $15 \mathrm{H}$-file (DENTSPLY Maillefer, Ballaigues, Switzerland) and canal wall then pulling it out coronally followed by copious irrigation with normal saline \& $5.2 \%$ sodium hypochlorite.

\section{Conclusion}

As a foreign object can act as a source of discomfort, pain and foci of infection, prompt but cautious attempts should be made to retrieve it first by simple nonsurgical means. In this case the foreign object was bypassed with a fine ISO no $15 \mathrm{H}$-file (DENTSPLY Maillefer, Ballaigues, Switzerland) and retrieval was done by attempting to engage the stapler pin between ISO no. $15 \mathrm{H}$-file (DENTSPLY Maillefer, Ballaigues, Switzerland) and canal wall and then pulling it out coronally followed by copious irrigation. In the present case this technique proved to be successful in retrieving the foreign body from the root canal. Although it seems to be a simple technique it may not be employed in the removal of all types of foreign bodies from the root canals. However it may be included as an alternative way for the removal of foreign bodies as it causes little or no loss of internal tooth structure.

\section{References}

1. Prabhakar AR, Basappa N, Raju OS. Foreign body in a mandibular permanent molar: A case report. J Ind Soc Pedod Prev Dent. 1998; 16: 120-121.

2. Nernst H. Foreign body in the root canal. Quintessence. 1972; 23: 26.

3. Aduri R, Reddy RE, Kiran K. Foreign objects in teeth: Retrieval and management. J Ind Soc Pedod Prev Dent. 2009; 27: 179-183.

4. SubbaReddy VV, Mehta DS. Beads. Oral Surg Oral Med Oral Pathol. 1990; 69: 769-770.

5. Hall JB. Endodontics - Patient performed. J Dent Child. 1969; 36: 213-216.

6. Kataoka SHH, Okai W, Caldeira CL. Removal of a nail into the root canal: case report. J Health Sci Inst. 2010; 28: 141-143.

7. Toida $\mathrm{M}$, Ichihara $\mathrm{H}$, Okutomi $\mathrm{T}$, Nakarmura $\mathrm{K}$, Ishimaru JI. An unusual foreign body in an unerupted supernumerary tooth. Br Dent J. 1992; 173: 345-346.

8. Gadgil RM. Foreign incense. Br Dent J. 2009; 207: 305.

9. Friedman S, Stabholtz A, Tamse A. Endodontic retreatment case selection and techniques: 3 retreatment techniques. J Endod. 1990; 16: 543-549.

10. Stewart GG. Chelation and floatation in endodontic practice: An update. J Am Dent Assoc. 1986; 113: 618-622. 
11. Meidinger DL, Kabes BJ. Foreign object removal utilizing the caviendo ultrasonic instrument. J Endod. 1985; 11: 301-304.

12. Williams VD, Bjourndal AM. The Masseran technique for the removal of fractured posts in endodontically treated teeth. J Prosthet Dent. 1983; 49 46-48

13. Fros UG, Berg JO. A method for the removal of broken endodontic instruments from the root canals. J Endod. 1983; 9: 156-159.

14. Roig-Greene JL. The retrieval of foreign objects from root canals: A simple aid. J Endod. 1983; 9: 394-397.

15. Nehme WB. Elimination of intracanal metallic obstruction by abrasion using an operational microscope and ultrasonics. J Endod. 2001; 27: 365-367.

16. Srivastava N, Vineeta N. Foreign body in the periradicular area. J Endod 2001; 27: 593-594
17. McCullock AJ. The removal of restorations and foreign objects from root canals. Quintessence Int. 1993; 24: 245-249.

18. Walvekar SV, Al- Duwari Y, Al-Kandri AM, Al-Quoud OA. Unusual foreign objects in the root canal. J Endod. 1995; 21: 526-527.

19. Goldstein BH, Scuibba JJ, Laskin DM. Actinomycosis of the maxilla: A review of literature and a report case. J Oral Surg. 1972; 30: 362-366.

20. Costa F, Robiomy M, Toro C, Sembronio S, Politi M. Endoscopically assisted procedure for the removal of a foreign body from the maxillary sinus and contemporary endodontic surgical treatment of the tooth. Head Face Med. 2006; 8: 37.
Austin J Dent - Volume 4 Issue 2 - 2017

ISSN : 2381-9189 | www.austinpublishinggroup.com

Manjunath et al. (C) All rights are reserved
Citation: Prabhakar AR, Saraswathi VN and Manjunath TG. Staple and Wooden Diet: Foreign Bodies in a Traumatised Tooth with Periapical Pathology. Austin J Dent. 2017; 4(2): 1070. 